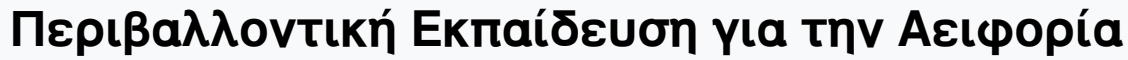

Tóp. 2, Ap. 2 (2020)

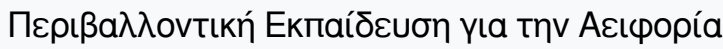

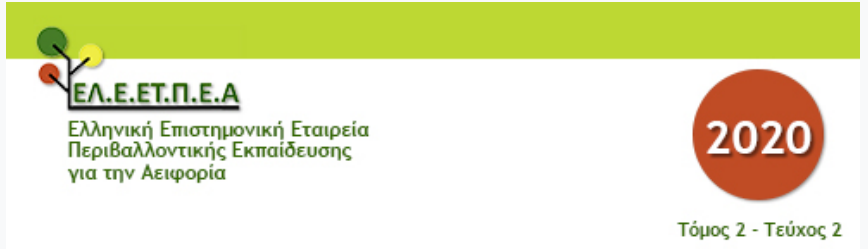

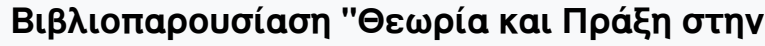

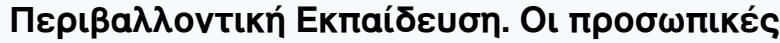

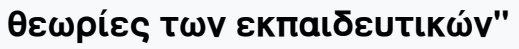

EA.E.ET. П.E.A.

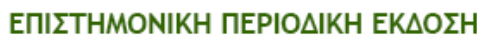

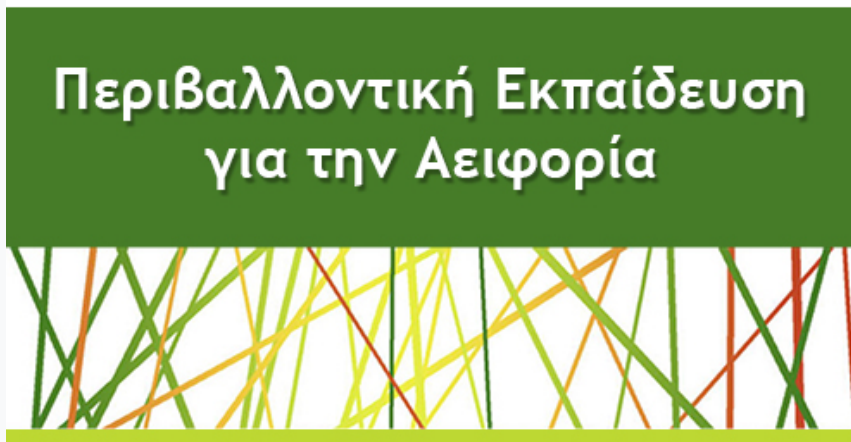

doi: $10.12681 /$ ees.25371

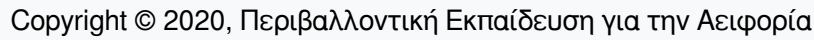

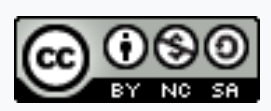

ISSN: $2585-3813$

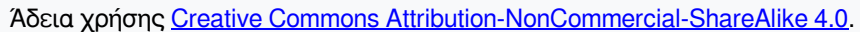

\section{Bıß入ıорафıкń avaџopá:}

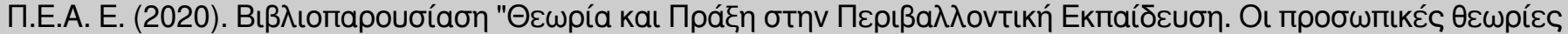

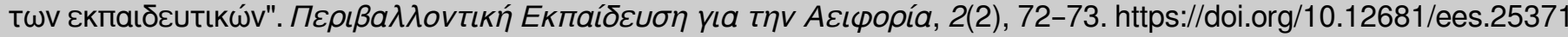




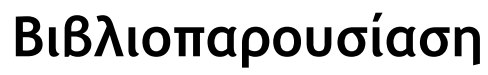

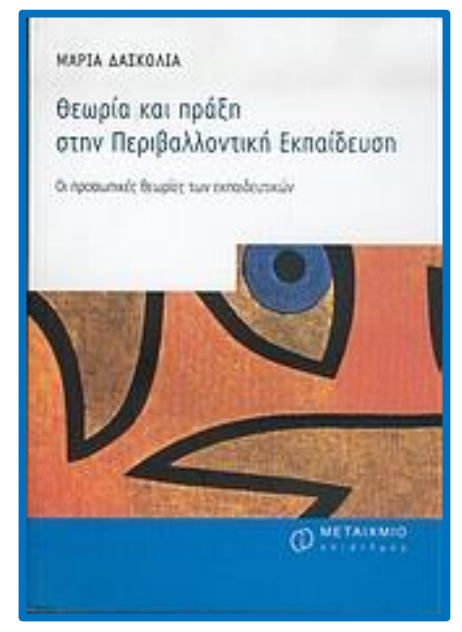

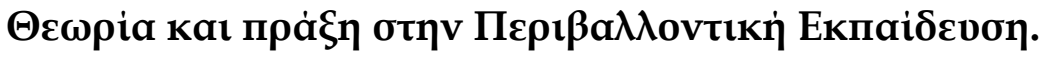

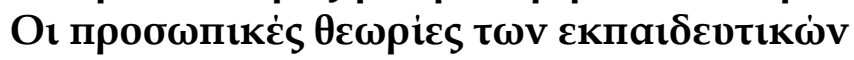

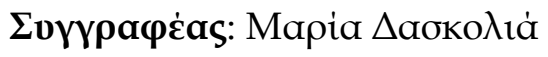

X

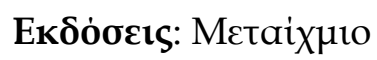

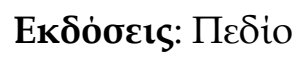

ISBN: 978-960-375-834-1

$\Sigma \varepsilon \lambda i \delta \varepsilon$ : 228

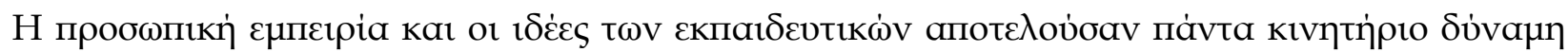

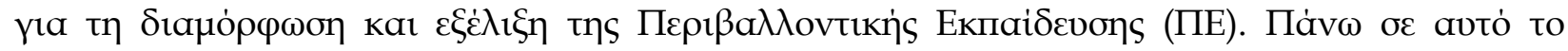

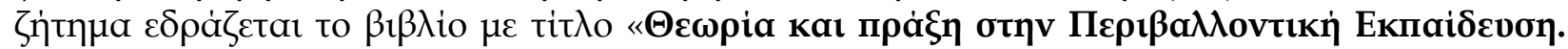

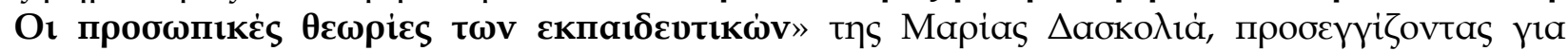

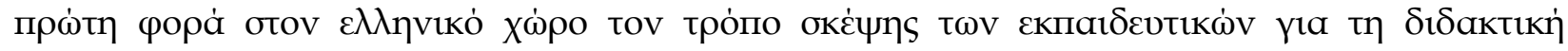

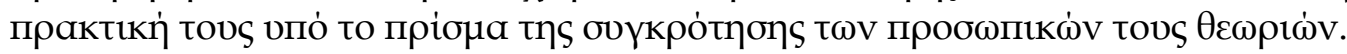

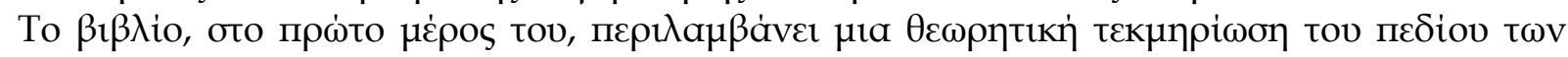

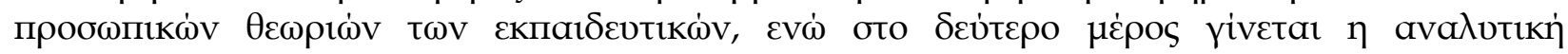

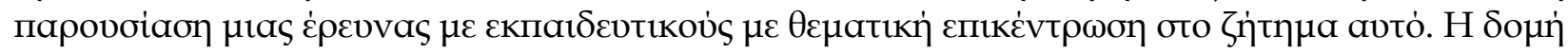

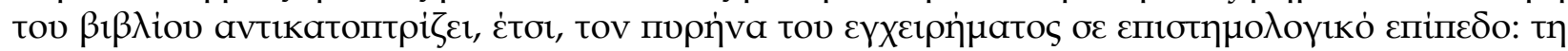

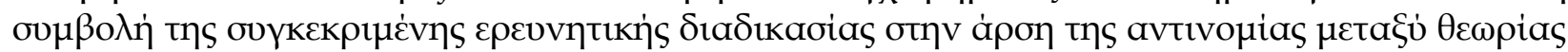

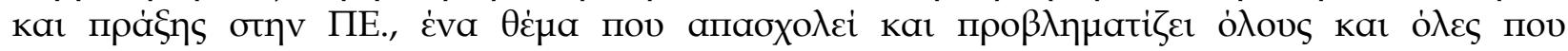

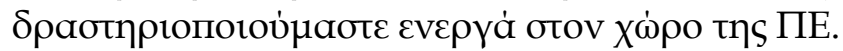

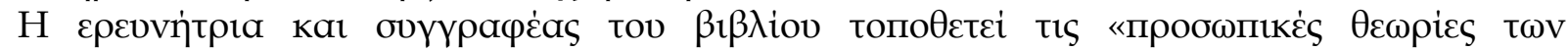

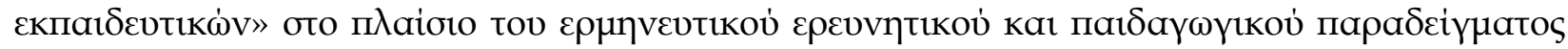

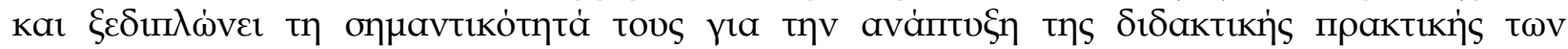

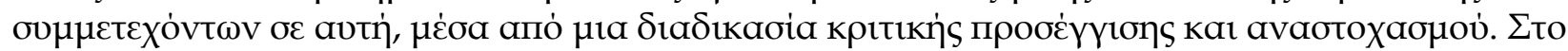

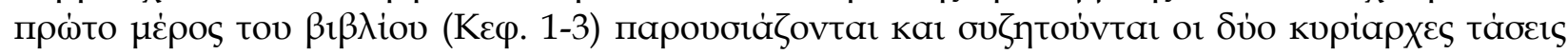
otov $\chi \dot{\omega} \rho$ tᄁ

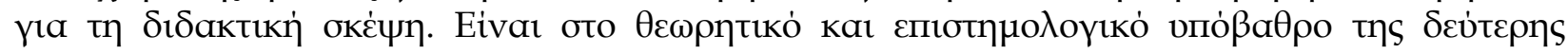

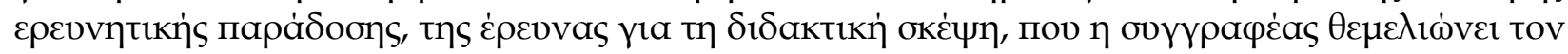

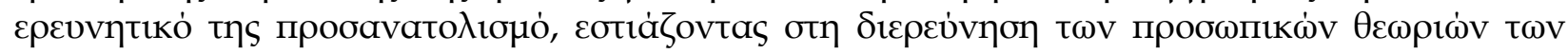
$\varepsilon \kappa \Pi а \iota \delta \varepsilon v t \imath \kappa \dot{v}$.

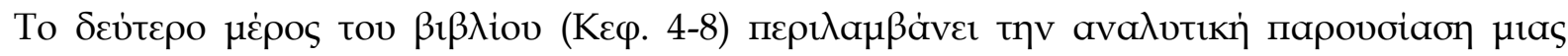

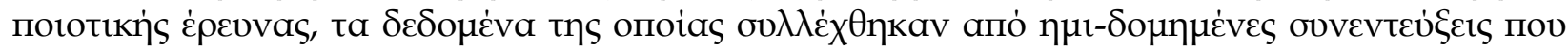

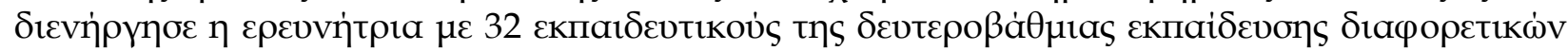

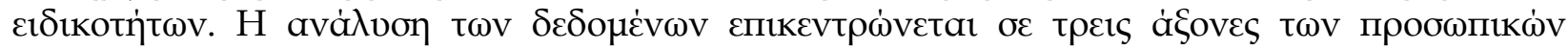

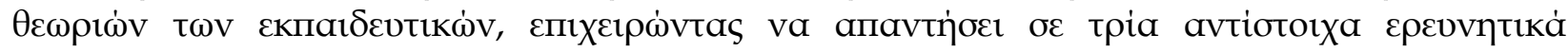

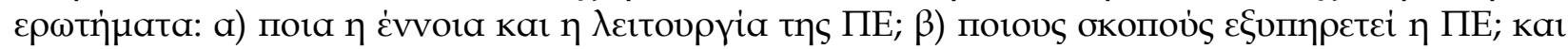

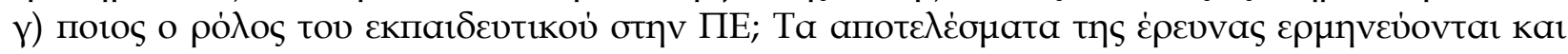

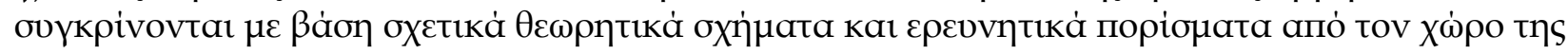

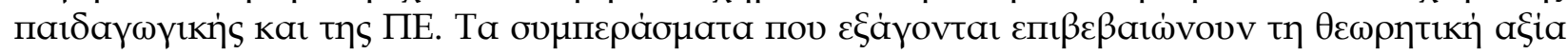

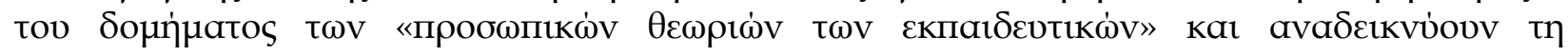

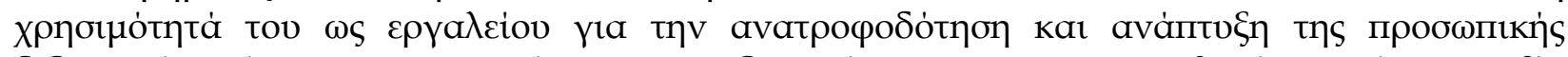

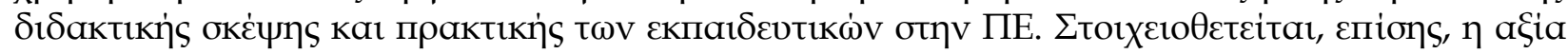




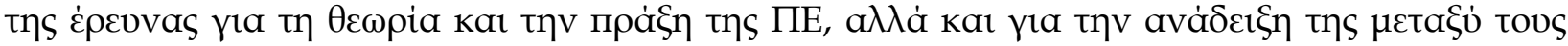

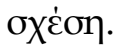

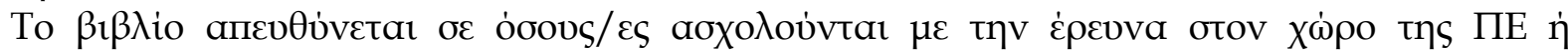

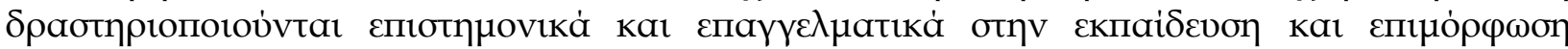

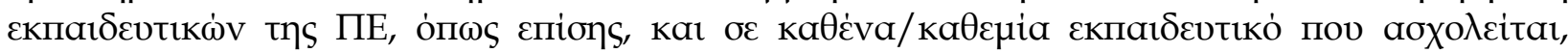

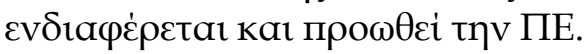

